ISSN 2227-7099

www.mdpi.com/journal/economies

Article

\title{
Access to Media and HIV Knowledge in India
}

\section{Smriti Agarwal ${ }^{1}$ and Pedro de Araujo ${ }^{2, *}$}

1 Royal Bank of Scotland, London, UK; E-Mail: smriti.agarwal18@gmail.com

2 Colorado College, Colorado Springs, CO 80903, USA

* Author to whom correspondence should be addressed; E-Mail: pedro@coloradocollege.edu;

Tel.: +1-719-389-6470; Fax: +1-719-389-6927.

Received: 25 October 2013; in revised form: 22 April 2014 / Accepted: 9 June 2014 /

Published: 18 June 2014

\begin{abstract}
This paper aims to better understand the relationship between HIV knowledge and media exposure in India. We use a two-stage hurdle model to estimate the effect of media sources such as newspapers, radios and television on AIDS-related knowledge among Indian men and women using demographic health survey data. Overall, access to newspapers, radio, or television increases the likelihood of better HIV knowledge in both males and females by an order between $2 \%$ and $12 \%$. These findings, albeit quantitatively small, suggest, even if indirectly, possible problems faced by AIDS campaigns and government programs in combating the HIV epidemic in India.
\end{abstract}

Keywords: HIV/AIDS; ordered probit; average partial effects; India

JEL Classification: O12, O53

\section{Introduction}

The HIV/AIDS epidemic, earlier prevalent in only a few countries and among selected groups of people, has brought serious concerns in the last few decades. The number of HIV positive individuals is increasing significantly all across the globe. According to the UNAIDS Joint United Programme on HIV/AIDS [1], since the beginning of the epidemic, almost 60 million people have been infected with HIV and 25 million people have died of HIV-related causes. Absence of a curable treatment or an effective vaccine makes the HIV infection deadly and, hence, its spread cannot be ignored. Previously thought of as a western health problem, HIV/AIDS was overlooked by most developing countries as a problem of homosexuals, drug users and westerners who engage in unsafe sexual practices. However, 
the recent emergence and spread of the HIV virus in several developing countries' populations has been met with a lot of dismay and denial. Currently, the African continent has the most HIV positive cases, followed by Asia. In the next 10 years, however, Asia is believed to have more HIV cases than that of any other continent [2].

The role of media in educating individuals on HIV/AIDS issues is uncertain. Media sources such as newspapers, radio and television constantly attempt to increase HIV/AIDS knowledge through advertisements, shows, and movies. Several government programs and AIDS organizations utilize media to convey AIDS information to citizens. However, at the same time, numerous newspaper, radio and television broadcasts increase misconceptions about AIDS by providing inaccurate or exaggerated AIDS information. Therefore, even though media has potential to educate people on HIV issues, the current impact of media on HIV knowledge is indeterminate.

The current paper, therefore, contributes to this discussion by investigating the association between media exposure and HIV related knowledge using the third wave of the demographic health survey. In the same lines as Aggarwal and Rous [3], this paper uses a two-stage hurdle model to infer the strength of this association. The main findings are that media exposure is positively associated with better knowledge, but the effect is quantitatively small. Also, there are some gender differentials in HIV knowledge with respect to media exposure. Moreover, these differentials are larger once media is interacted with work status.

HIV has spread largely through heterosexual intercourse in most developing countries, including Sub-Saharan Africa, China, India, Thailand, and Cambodia. The epidemic has moved from urban to rural areas and from high-risk populations to low-risk populations. Among heterosexuals, key links to rising levels of HIV/AIDS cases are economic instability and associated poverty, substance use, gender inequality and low levels of literacy (Ghosh [4]).

In India, the first HIV infection was reported in 1986 in a commercial sex worker in Madras (Kumar, Mudaliar, and Daniels [5]), and since then the number has increased to over 2 million. When AIDS first emerged in India, it was dismissed as a curse on the unscrupulous people engaging in corrupt behavior. In a predominantly Hindu-society, AIDS was, and in some regions still is, considered the disease of the untouchables and hence, no actions were taken to combat the infection for a long period of time. Ghosh [4] asserts that even though rural India appeared to have a lower incidence of HIV/AIDS than did the country's urban area, the rural prevalence rate is likely to be hidden because of the fear associated with AIDS. The high mobility of people between urban and rural areas is likely to increase HIV cases in India in the future.

The extremely large population of India poses a high threat in terms of the rapid spread of HIV infection. In the future, India is estimated to have the most number of HIV infected individuals. Eberstadt [6] estimates that the cumulative new HIV cases between 2000 and 2025 in India will be 30 million under a mild epidemic, 110 million in an intermediate epidemic and 140 million in a severe epidemic. Apart from the large population density, causes of the growing epidemic in India include stigma associated with infected people, cultural taboos against open discussion about sex, high levels of poverty and malnutrition in the poorest sectors, low literacy rate, lack of dedication and commitment to studying and controlling the disease, limited resources, high migration due to India's central location with respect to global trading and particularly, deficient communication between health officials, state governments and their communities (Keshavan [7]). 
The two main reasons for the high vulnerability of Indians to the HIV infection include poor knowledge about the disease and misconceived risk perceptions that results in unsafe sexual behavior, such as low use of condoms (de Araujo [8]). In developing countries, especially in India, which has an extremely low per capita income, most infected individuals cannot afford to pay for the expensive HIV treatment- antiretroviral drugs. Thus, prevention is the key step in controlling the infection in India and hence increasing awareness among individuals is highly important.

As technology becomes more accessible in the developing world, few studies have investigated the degree of media access and propagation in these populations (Jensen and Oster [9]), many of which suggest there is a role for media in affecting behavior and knowledge about HIV and other important issues (Johnson [10], Chatterjee [11], Pallikadavath, Sreedharan, and Stones [12]). There have also been studies linking media exposure or campaigns to sexual behavior and HIV/AIDS knowledge (Keating, Meekers, and Adewuyi [13], Bessinger, Katende, and Gupta [14], Jesmin, Chaudhuri, and Abdullah [15], and Bertrand and Anhanq [16]); however, up to our knowledge, the current paper is the first to conduct this investigation for India.

\section{Related Literature}

\subsection{Media Exposure among Indians}

The swift advancement of technology in the last few decades has significantly improved the access and use of media in most developing countries. According to Jensen and Oster [9], 30 million households in India added cable services in the 5-year span between 2001 and 2006. Media's far-reaching influence on the Indian populace is evident from the recent modernization of the country as well as people's emulation of what they perceive to be desirable behaviors and attitudes (Johnson [10]). Therefore, Indian television has the potential to affect the attitudes and behavior of most individuals, especially the young adults.

Regardless of the improvement in the livelihood of Indians brought through mass media technology, media's role in increasing HIV/AIDS knowledge has been somewhat limited. The cultural taboos associated with sex talk make an open conversation on HIV/AIDS transmission and prevention difficult. Chatterjee [11] observes that the conservative nature of Indian leaders like the Sushma Swaraj (health minister of India 2003), who dislike the idea of promoting condoms and impede TV advertisements because they might encourage sex, contributes to poor HIV/AIDS communication through television and other media sources in India.

The impact of mass media in communicating AIDS-related knowledge is not completely understood. Different media sources have varying effects. Sources like newspapers and radios are minimally used but television is used by majority of Indians. Thus, according to Pallikadavath, Sreedharan, and Stones [12] television broadcasts might be an effective medium to disseminate AIDS awareness. However, the vague and incomplete AIDS information presented on television and other media sources due to the numerous political and social barriers has limited the quality of AIDS knowledge in the Indian population. The inadequacy of media's role in providing quality AIDS knowledge also stems from the indirect and non-verbal communication about sex and sex-related issues among peers and family members in India (Lambert and Wood [17]). 


\subsection{HIV/AIDS-Related Knowledge}

Chatterjee [11] concludes that educating individuals about the risks associated with AIDS as well as increasing knowledge on the modes of HIV transmission and prevention is to be the first and most crucial step in battling the AIDS epidemic. Thus, the majority of HIV/AIDS campaigns and other prevention programs aim at increasing AIDS-related knowledge among all types of people in India, especially those living in rural areas because of their limited access to education from other sources.

Albeit changing in urban areas recently, social norms and cultural traditions in India that are core to the living style of most people have persistently encouraged men to gain higher education, while women are expected to excel at domestic household work. The gender relations in India have hindered equal opportunity for both men and women. Hence, overall HIV/AIDS knowledge tends to be higher in men compared to that of women in India ${ }^{1}$. However, the level of AIDS-related knowledge among men is also based on other factors such as media access, residence location, education level and wealth (de Araujo [8]). AIDS knowledge varies significantly across different groups of men, ranging from those who have never heard of the disease to those that have complete and accurate knowledge about the disease; this is also true for women.

Social relations and gender dynamics, particularly in rural areas limit open discussions on HIV/AIDS related topics and discourage women from making independent choices. Thus, it is important to increase knowledge levels among women so that they have greater autonomy in making their own decisions and controlling their sexual life. Although the majority of Indian women had heard of AIDS, quality knowledge was extremely low in the early 2000s. During 1998-2000, 70\% of rural and $30 \%$ of urban ever-married women lacked AIDS awareness (Pallikadavath, Sreedharan, and Stones [12]). Also, even though $45 \%$ of the women had heard of AIDS, only $21 \%$ knew condoms as a mode of prevention. Thus, the quality of AIDS-related knowledge has remained relatively poor among Indian women.

In India, it is expected that young, single women are virgins and ignorant of sexual matters. The chastity of young women is seen as their most desirable virtue for purpose of marriages. As a result, most unmarried women lack knowledge on how to protect themselves from STDs and are incapable of gaining that knowledge after their marriage due to the suppressed role in their husbands' family. Thus, women, especially in rural areas who are obstructed from useful knowledge on sexual safety, are at high risk of acquiring HIV. Also, because of financial dependence, women have low bargaining power in sexual relationships and are unable to convince their spouses to use condoms, especially if their own knowledge about the disease is poor. Thus, to have a persuasive power in changing their husband's behavior, women need to have enhanced knowledge on AIDS.

Women's knowledge of HIV/AIDS in India also differs based on the socioeconomic factors of each woman. Although media use such as television increases AIDS awareness among women, it does not significantly improve the quality of knowledge (Ghosh, Wadhwa, and Kalipeni [18]). According to Aggarwal and Rous [3], women's education level is one factor that is significantly associated with improved quality of AIDS-related knowledge. Also, the number of sources from which women receive

\footnotetext{
${ }^{1}$ Descriptive statistics from various waves of the demographic health surveys of different developing countries, including India, corroborates this assertion.
} 
AIDS information is significantly related to the quality of knowledge (Gupta et al. [19]). Thus, emanating AIDS-related knowledge through a variety of diverse sources will help women understand the serious implications of risky sexual behavior and encourage them to take a stance in order to protect themselves.

\section{Data and Descriptive Statistics}

The data source for this paper is the 2005-06 National Family Health Survey (NFHS-3) [20] released by the Ministry of Health and Family Welfare in New Delhi in 2007. The report offers the first-ever comprehensive picture of the health and well-being of India's men, women, and children. The dataset is available and obtained through the MEASURE DHS website. NFHS-3, the third in the NFHS series of surveys provides information on population, health and nutrition in India and in each of its 29 states. NFHS-3 interviewed women age 15-49 and men age 15-54. The survey is based on a sample of households, which is representative at the national and state levels. NFHS-3 conducted interviews with almost 199,000 women and men throughout India and also tested more than 100,000 women and men for HIV. Table 1 provides a description of every variable used in the analysis and Tables 2 and 3 displays important descriptive statistics.

For the first time, the survey measured HIV prevalence at the national level and for selected states (Andhra Pradesh, Karnataka, Maharashtra, Manipur, Tamil Nadu, and Uttar Pradesh). The NFHS-3 survey [20] found an HIV prevalence rate of $0.28 \%$ for the population age 15-49. The important new information about HIV prevalence from NFHS-3 has spurred the Government of India and international agencies to greatly reduce the official estimate of Indians living with HIV from more than 5 million persons to 2.47 million. This change has had a major impact on the global estimate of persons living with HIV. At the same time, the estimate of AIDS cases in India for upcoming decades causes concerns among the government and AIDS organizations.

The Demographic and Health Surveys have been asking questions about HIV/AIDS knowledge, attitudes and behaviors since 1988. Indicators include knowledge of HIV prevention methods, attitudes towards those living with AIDS, beliefs about AIDS transmission and experiences with higher-risk sex, including paid sex. The NFHS is divided into different categories-males, females, household, couples, children and several others based on the people interviewed. This paper analyzes AIDS-related knowledge and behavior of males and females, thus the variables for this paper are selected from the male and female recode files. 
Table 1. Description of variables.

\begin{tabular}{|c|c|c|}
\hline Var & Description & Details \\
\hline \multicolumn{3}{|c|}{ HIV awareness } \\
\hline EHA & AIDS awareness & $=1$ if respondent has ever heard of AIDS; $=0$ otherwise \\
\hline \multicolumn{3}{|c|}{ HIV specific knowledge } \\
\hline KCU & Knowledge of condoms & $\begin{array}{l}=1 \text { if respondent knows that one can reduce chances of } \\
\text { AIDS by using condoms during sex; }=0 \text { otherwise }\end{array}$ \\
\hline KSP & Knowledge of sexual partners & $\begin{array}{l}=1 \text { if respondent knows that one can reduce chances of } \\
\text { AIDS by having } 1 \text { sex partner with no other partner; } \\
=0 \text { otherwise }\end{array}$ \\
\hline KSF & Knowledge on sharing food & $\begin{array}{l}=1 \text { if respondent knows that one cannot get AIDS by } \\
\text { sharing food with infected person; }=0 \text { otherwise }\end{array}$ \\
\hline HLP & Healthy looking person & $\begin{array}{l}=1 \text { if respondent knows that a healthy looking person can } \\
\text { have AIDS; }=0 \text { otherwise }\end{array}$ \\
\hline \multicolumn{3}{|c|}{ Media variables } \\
\hline NWP & Frequency of reading newspapers & $\begin{array}{l}=1 \text { if respondent reads newspaper at least once a week; } \\
=0 \text { otherwise }\end{array}$ \\
\hline FLR & Frequency of listening to radio & $\begin{array}{l}=1 \text { if respondent listens to radio at least once a week; } \\
=0 \text { otherwise }\end{array}$ \\
\hline FWT & Frequency of watching television & $\begin{array}{l}=1 \text { if respondent watches television at least once a week; } \\
=0 \text { otherwise }\end{array}$ \\
\hline \multicolumn{3}{|c|}{ Other variables } \\
\hline EDUC & Education level & $\begin{array}{l}\text { Four categories: no education, primary, secondary, and } \\
\text { higher education }\end{array}$ \\
\hline WEALTH & Wealth index & $\begin{array}{l}\text { Five categories (quintiles): poorest, poorer, middle, richer, } \\
\text { and richest }\end{array}$ \\
\hline LOC & Type of residence location & Two categories: urban and rural \\
\hline MS & Marital status & $\begin{array}{l}\text { Three categories: never married, currently married, and } \\
\text { formerly married }\end{array}$ \\
\hline AGE & Age in years & Ages between 15 and 54 \\
\hline WORK & Current work status & Two categories: currently working or not \\
\hline RELIGION & Religion of respondent & $\begin{array}{l}\text { Eleven categories: Hindu, Muslim, Christian, Sikh, } \\
\text { Buddhist/Neo-Buddhist, Jain, Jewish, Parsi/Zoroastrian, } \\
\text { Donyi Polo, Other, and no religion }\end{array}$ \\
\hline STATE & State of residence & 29 States and Territories recorded \\
\hline CASTE & Caste or tribe status & $\begin{array}{l}\text { Four categories: scheduled caste, scheduled tribe, other } \\
\text { backward class, and none of them }\end{array}$ \\
\hline
\end{tabular}

\subsection{Media Use}

The use of newspapers, radio and television in India has been increasing significantly in the past few decades because of recent innovations in the field of technology and India's evolving role in the world economy (Jensen and Oster [9]). Based on the NFHS-3 [20], the most used media source among both men and women in India is television. On average, $71.7 \%$ of Indian men and $64.7 \%$ of Indian women watch television at least once a week or more. This indicates the stretch of television access from urban to rural India. These numbers are presented in Table 2. The lower use of television by 
women as compared to that by men is possibly due to higher percentage of women living in rural areas $(54.2 \%)$ as compared to the percentage of men living in rural areas (48.6\%), where access to television is more limited.

Table 2. Summary statistics of variables.

\begin{tabular}{ccccccc}
\hline \multirow{2}{*}{ Variable } & \multicolumn{3}{c}{ Males } \\
\cline { 2 - 6 } & Mean & Std. Dev. & Obs. & Mean & Std. Dev. & Obs. \\
\hline \multicolumn{7}{c}{ Media variables } \\
\hline NWP (newspapers) & 0.58 & 0.49 & 74,304 & 0.30 & 0.46 & 124,276 \\
FLR (radio) & 0.47 & 0.50 & 74,356 & 0.32 & 0.47 & 124,352 \\
FWT (television) & 0.72 & 0.45 & 74,360 & 0.65 & 0.48 & 124,361 \\
\hline & AIDS awareness and specific knowledge \\
\hline EHA & 0.89 & 0.32 & 74,362 & 0.71 & 0.45 & 124,374 \\
KCU & 0.84 & 0.37 & 65,940 & 0.64 & 0.48 & 88,350 \\
KSF & 0.77 & 0.42 & 65,969 & 0.73 & 0.44 & 88,352 \\
KSP & 0.88 & 0.33 & 65,987 & 0.76 & 0.43 & 88,376 \\
HLP & 0.77 & 0.42 & 65,993 & 0.67 & 0.47 & 88,382 \\
\hline AGE & 30.93 & 10.77 & 74,369 & 29016 & 9.49 & 124,385 \\
LOC_1 (Urban) & 0.51 & 0.50 & 74,369 & 0.46 & 0.50 & 124,385 \\
EDUC_1 (No education) & 0.14 & 0.35 & 74,338 & 0.32 & 0.47 & 124,373 \\
EDUC_2 (Primary) & 0.15 & 0.36 & 74,338 & 0.14 & 0.35 & 124,373 \\
EDUC_3 (Secondary) & 0.55 & 0.50 & 74,338 & 0.43 & 0.50 & 124,373 \\
EDUC_4 (Higher) & 0.15 & 0.36 & 74,338 & 0.10 & 0.31 & 124,373 \\
MS_1 (Never married) & 0.38 & 0.49 & 74,369 & 0.25 & 0.43 & 124,385 \\
MS_2 (Currently married) & 0.60 & 0.49 & 74,369 & 0.71 & 0.46 & 124,385 \\
MS_3 (Formerly married) & 0.01 & 0.12 & 74,369 & 0.05 & 0.21 & 124,385 \\
WORK_1 (Not working) & 0.16 & 0.37 & 74,339 & 0.65 & 0.48 & 124,122 \\
\hline & \multicolumn{7}{c}{ Other variables }
\end{tabular}

The use of other media sources such as radio (FLR) and newspapers (NWP) is considerably low compared to television (FWT) use. For instance, only $58.3 \%$ of the men and $30.3 \%$ of the women read newspapers at least once a week or more. The lesser use of newspapers is due to the low literacy rate in India (Lambert and Wood [17]). As compared to the number of men, only half as many women read newspapers frequently. Thus, from the difference in the use of newspapers between men and women, it is evident that on average women are less educated as compared to men. Moreover, the use of radio is even lower than the use of newspapers for men and radio's use among women is similar to their use of newspapers. Thus, AIDS programming on radios are unable to reach the majority of people, however, it is vital to disseminate AIDS knowledge through radios because of its easy access and use among high-risk groups like truck drivers, migrant workers, and sex workers (Jayasree [21]).

\subsection{Knowledge on AIDS}

Six variables are used to capture Indian men and women's knowledge on AIDS-related matters. A detailed description of these variables can been found in Table 1. The general awareness of AIDS is measured through EHA, knowledge on modes of AIDS transmission and prevention is measured 
through KCU and KSP, and knowledge on AIDS-related stigma is found through KSF and HLP. All these variables have binary outcomes of 0 and 1 , with 0 representing no knowledge and 1 representing accurate knowledge. Based on the means of all these variables in Table 2, it appears that women's knowledge about HIV is more limited. While $88.8 \%$ of men have heard of AIDS, only $71.7 \%$ of women have ever heard of AIDS. Thus, around 30\% of Indian women are unaware of AIDS and are more likely to acquire it compared to women who know about the disease, ceteris paribus.

The poor knowledge of AIDS among women reduces their ability to convince men to engage in safe sexual practices. For instance, only $64.2 \%$ of the women know that one can reduce chances of acquiring AIDS by using condoms (KCU). Hence, around $35 \%$ of the women cannot tell their partners to use condoms because they are unaware of the advantages of condom use. These statistics suggest that a great number of Indians does not completely understand the disease and has various misconceptions about AIDS. For instance, more than $20 \%$ of men and women think that sharing food with an infected person can transmit HIV. Thus, AIDS-related stigma is something that most likely still exists in India.

\subsection{Control Variables}

To account for variation in AIDS-related knowledge and sexual behavior that might be due to differences in location, religion, age, marital status, state of residence, education level, wealth, and work status, this paper uses several control variables. A complete description of these variables is available in Table 1.

Based on mean values of the control variables in Table 2, there is a lot of variation among Indian men and women. For example, $14.4 \%$ of men and $32 \%$ of women do not have even primary education. This is very alarming, especially since AIDS-related knowledge and safe sexual behavior is positively correlated with increasing educational levels. The majority of respondents were currently married: $60.4 \%$ of interviewed men were married and $70.7 \%$ of interviewed women were married. More women are married as compared to men probably because of the domestic role of women in India. Additionally, $83.5 \%$ of men said they were currently working while only $35.2 \%$ of women said they were currently working. Thus, it is important to encourage work among women because financial independence will enable women to take control of their sexual lives.

The difference in the location of individuals' residence is important because of factors such as limited access to media sources such as television and limited availability of condoms in rural areas (Johnson [10]). On average, $45.6 \%$ of women and $51.4 \%$ of men live in urban areas. Thus, the majority of women and around half of men live in rural areas. Civilizing the livelihood of rural residents might be an important and essential step in improving sexual behavior and AIDS knowledge in India (Ghosh [18]). Table 3 displays mean values of all variables separating the sample by location of residence. It is obvious that individuals living in rural areas have less exposure to media, less HIV knowledge, and less education compared to individuals living in urban areas. Moreover, these differentials are somewhat larger for women. Hence, it becomes important to investigate the effects of media exposure on HIV knowledge for these four subsamples independently. 
Table 3. Mean values by location of residence.

\begin{tabular}{|c|c|c|c|c|}
\hline \multirow{2}{*}{ Variable } & \multicolumn{2}{|c|}{ Male } & \multicolumn{2}{|c|}{ Female } \\
\hline & Urban & Rural & Urban & Rural \\
\hline \multicolumn{5}{|c|}{ Media variables } \\
\hline NWP & 0.702 & 0.457 & 0.451 & 0.176 \\
\hline FLR & 0.470 & 0.467 & 0.340 & 0.299 \\
\hline FWT & 0.858 & 0.495 & 0.841 & 0.483 \\
\hline \multicolumn{5}{|c|}{ AIDS awareness and specific knowledge } \\
\hline EHA & 0.958 & 0.813 & 0.862 & 0.582 \\
\hline $\mathrm{KCU}$ & 0.861 & 0.808 & 0.695 & 0.574 \\
\hline KSF & 0.827 & 0.704 & 0.786 & 0.669 \\
\hline KSP & 0.897 & 0.853 & 0.794 & 0.717 \\
\hline HLP & 0.810 & 0.713 & 0.718 & 0.606 \\
\hline \multicolumn{5}{|c|}{ Other variables } \\
\hline AGE & 30.76 & 31.10 & 29.4 & 28.95 \\
\hline EDUC_1 (No education) & 0.088 & 0.202 & 0.193 & 0.426 \\
\hline EDUC_2 (Primary) & 0.119 & 0.191 & 0.115 & 0.166 \\
\hline EDUC_3 (Secondary) & 0.570 & 0.524 & 0.509 & 0.368 \\
\hline EDUC_4 (Higher) & 0.221 & 0.081 & 0.182 & 0.038 \\
\hline MS_1 (Never married) & 0.424 & 0.339 & 0.280 & 0.217 \\
\hline MS_2 (Currently married) & 0.565 & 0.644 & 0.673 & 0.734 \\
\hline MS_3 (Formerly married) & 0.004 & 0.009 & 0.045 & 0.047 \\
\hline WORK_1 (Not working) & 0.183 & 0.147 & 0.717 & 0.591 \\
\hline
\end{tabular}

\section{Empirical Model and Methodology}

In order to capture the association between media access and HIV knowledge among men and women in India, the empirical strategy adopted in this paper follows that of Aggarwal and Rous [3]. In the demographic health surveys there are two stages of knowledge questions. In the first stage, respondents are asked if they are aware of AIDS; in the second stage, respondents are asked more specific questions about the disease (see Table 1). Only the respondents who are aware of AIDS are asked the more specific HIV knowledge questions. Hence, the second stage questions are conditioned on the first stage responses.

This survey design allows for the estimation of a hurdle model, where in the first stage we estimate an awareness equation and in the second stage we estimate a specific knowledge or quality of knowledge equation ${ }^{2}$.

The first stage model is given by:

$$
\mathrm{P}\left(\mathrm{EHA}_{i}=1 \mid M, X\right)=F\left(\alpha+\beta M_{i}+X_{i}^{\prime} \psi\right)
$$

Where $\mathrm{P}$ is the probability of event EHA occurring, EHA is the variable of interest that captures if an individual $i$ has ever heard of AIDS, $M$ is a variable that captures media exposure, that is, the frequency to which individuals use a particular media source, and $X$ is a vector of controls that includes: wealth, education, location of residence, work status, age, marital status, State of residence,

\footnotetext{
${ }^{2}$ This model can be estimated by estimating each stage independently (Wooldridge [22]).
} 
and religion, $F$ is the normal cdf, and $\alpha, \beta$, and $\psi$ are parameters to be estimated. All of these controls have been widely used in such models. Equation (1) above is estimated three times for each gender as we separate exposure to media into television, radio, and newspapers.

In the second stage we estimate multiple probit regressions similar to Equation (1), where the dependent variable is each specific knowledge question found in Table 1. This model captures the association between different media sources and specific knowledge about HIV.

In order to capture the association between knowledge quality and media, we estimate an ordered probit model in the second stage where the dependent variable is a count variable in which we add the correct responses to all specific knowledge questions. That is, if the sum is zero, the respondent has no specific knowledge about HIV. If the sum is equal to 4, then the respondent has very good specific knowledge about HIV. Hence, moving from zero to 4 represents an increase in the quality in which respondents have about specific HIV-related knowledge questions. Later in the paper, we divide the sample into four categories: male urban, male rural, female urban, and female rural and estimate separate models for each.

Lastly, we calculate and only report average partial effects of the variables described above, with the exception of interactions. We follow Bartus [23] procedure to capture the appropriate magnitude of these associations. In what follows, we will report and discuss our results.

\section{Results and Discussion}

\subsection{Newspapers (NWP)}

Despite the low literacy rate in India, newspapers have had a significant effect in increasing HIV/AIDS related knowledge based on the 2005-2006 national demographic data results. According to the probit model, an increase use of newspapers improves HIV/AIDS knowledge among both men and women. The role of newspapers in promoting quality knowledge on HIV was limited until the early 2000s based on the previous wave of the NFHS data conducted in 2000. Earlier, newspapers were successful in increasing HIVAIDS stigma among educated individuals, but they did not provide any objective knowledge on modes of prevention and transmission (de Souza [24]). However, the establishment of several new campaigns and the recent help from the government has altered the function of newspapers in HIV/AIDS education. Thus, the effectiveness of newspapers in educating individuals on HIV has enhanced significantly since the late 1990s and early 2000s due to changing perceptions and removal of customary social barriers.

Among Indian men, newspapers have not only increased HIV/AIDS awareness, but also reduced stigma and improved the quality of HIV/AIDS knowledge. Based on the average partial effect estimations, men who read newspapers at least once a week are 6.6\% more likely to hear about AIDS compared to men who read newspapers less than once a week (Table 4). Also, Table 4 shows that men who read the newspaper at least once a week are $6.4 \%$ more likely to know that condom use is a preventive strategy and $4.7 \%$ more likely to know that having few sexual partners reduces their chances of acquiring HIV. Thus, knowledge on modes of HIV transmission and prevention is improving through newspapers. Also, stigma associated with AIDS is now being removed by media sources like newspapers. This is evident from the data, which shows that men who read newspapers 
are more likely to know that healthy looking people can have AIDS and HIV is not transmitted by sharing food with infected individuals. In summary, men who read newspapers on a regular basis are likely to benefit by receiving accurate AIDS knowledge.

Table 4. Average partial effects of media variables and interaction effects.

\begin{tabular}{|c|c|c|c|c|c|c|c|c|}
\hline \multirow{3}{*}{ Newspaper } & \multicolumn{4}{|c|}{ Male } & \multicolumn{4}{|c|}{ Female } \\
\hline & \multicolumn{4}{|c|}{ Overall (EHA) $0.066 * * *$} & \multicolumn{4}{|c|}{ Overall (EHA) $0.088 * * *$} \\
\hline & KCU & KSP & KSF & HLP & KCU & KSP & KSF & HLP \\
\hline NWP & $0.064 * * *$ & $0.047 * * *$ & $0.088 * * *$ & $0.337 * * *$ & $0.085 * * *$ & $0.067 * * *$ & $0.073 * * *$ & $0.062 * * *$ \\
\hline $\mathrm{ED} 2 * \mathrm{NWP}$ & 0.048 & 0.035 & $-0.226 * *$ & -0.062 & $-0.233 *$ & -0.137 & -0.178 & $-0.24 * *$ \\
\hline ED3*NWP & -0.003 & -0.035 & $-0.223 * *$ & -0.069 & $-0.193 *$ & -0.072 & -0.099 & -0.140 \\
\hline ED4*NWP & 0.026 & -0.0150 & -0.134 & -0.091 & $-0.237 * *$ & -0.116 & -0.160 & $-0.21 *$ \\
\hline WK2*NWP & -0.045 & -0.0002 & -0.050 & -0.015 & $0.127 * * *$ & $0.074 * * *$ & $0.094 * * *$ & $0.082 * * *$ \\
\hline \multirow{2}{*}{ Radio } & \multicolumn{4}{|c|}{ Overall (EHA) 0.0377 **** } & \multicolumn{4}{|c|}{ Overall (EHA) 0.0692 *** } \\
\hline & KCU & KSP & KSF & HLP & KCU & KSP & KSF & HLP \\
\hline FLR & $0.035 * * *$ & $0.027 * * *$ & $0.047 * * *$ & $0.032 * * *$ & $0.051 * * *$ & $0.046 * * *$ & $0.036 * * *$ & $0.027 * * *$ \\
\hline $\mathrm{ED} 2 * \mathrm{FLR}$ & 0.010 & -0.023 & 0.012 & 0.027 & -0.013 & -0.007 & -0.028 & $-0.087 * *$ \\
\hline ED3*FLR & -0.027 & -0.048 & 0.026 & 0.002 & -0.019 & 0.006 & 0.022 & $-0.055 * *$ \\
\hline ED4*FLR & $-0.13 * * *$ & $-0.11 * *$ & -0.024 & -0.068 & -0.021 & 0.019 & $0.104 * *$ & $-0.13 * * *$ \\
\hline WK2*FLR & -0.029 & $-0.072 * *$ & 0.050 & -0.009 & $0.055 * *$ & 0.005 & 0.007 & $0.039 *$ \\
\hline \multirow{2}{*}{ Television } & \multicolumn{4}{|c|}{ Overall (EHA) 0.0541 *** } & \multicolumn{4}{|c|}{ Overall (EHA) $0.1227 * * *$} \\
\hline & KCU & KSP & KSF & HLP & KCU & KSP & KSF & HLP \\
\hline FWT & $0.040 * * *$ & $0.029 * * *$ & $0.056 * * *$ & $0.049 * * *$ & $0.075 * * *$ & $0.047 * * *$ & $0.069 * * *$ & $0.036 * * *$ \\
\hline $\mathrm{ED} 2 * \mathrm{FWT}$ & -0.041 & 0.005 & $0.074 *$ & -0.029 & -0.003 & 0.010 & -0.011 & -0.041 \\
\hline ED3*FWT & -0.036 & 0.024 & $0.101 * * *$ & 0.013 & $0.072 * *$ & $0.082 * * *$ & $0.115 * * *$ & $0.081 * * *$ \\
\hline $\mathrm{ED} 4 * \mathrm{FWT}$ & -0.050 & -0.008 & $0.149 * *$ & 0.031 & $-0.103 *$ & -0.022 & 0.039 & -0.083 \\
\hline WK2*FWT & 0.066 & -0.017 & $0.077 *$ & 0.029 & $0.072 * * *$ & -0.011 & $0.050 * *$ & -0.0005 \\
\hline
\end{tabular}

*** Significant at $1 \%, * *$ significant at $5 \%$, significant at $10 \%$. Robust standard errors computed in every estimation. Coefficients on interactions estimated from probit regressions - not average partial effects. ED captures education (no education, primary, secondary, and higher education), WK2 captures work status.

As for women, the effectiveness of newspapers in increasing HIV/AIDS awareness is higher compared to that of men. Women who read newspapers at least once a week are $8.8 \%$ more likely to hear of AIDS. Also, the increase in knowledge on modes of transmission and prevention from reading newspapers is higher among women. The higher numbers could be due to the recent focus of campaigns and media sources on Indian women as victims of the AIDS epidemic. Tragic stories of India women getting AIDS from their disloyal husbands and fighting the infection with no support from families have increased women's interest in learning about the disease and preventing themselves. However, newspaper's role in removing misconceptions about AIDS has been limited among women. Only, $6.2 \%$ of the women who read newspapers at least once a week are likely to know that a healthy looking person can have AIDS. Thus, steps need to be taken to reduce HIV/AIDS stigma among Indian women, especially those living in rural areas. The conservative attitude of rural women has lead to the minimal impact of contemporary newspapers in removing current misconceptions about AIDS. 
The effect of newspapers varies greatly across different states based on regional newspaper broadcasts, state government's responses and literacy rate. The effect of newspapers is minimal not only because of its barely recent improvement in providing accurate and objective knowledge, but also because it targets only a small group of individuals, specifically those who know how to read and have access to newspapers. Hence, later in the paper we analyze the effect that different educational levels have in influencing the average partial effects of newspaper (and other media sources) on HIV knowledge.

\subsection{Radio (FLR)}

For majority of India, where access to television is absent in most rural areas and where a significant proportion of individuals are illiterate, radio is the optimal media source to disseminate knowledge to the entire populace. The easy access to radio among all individuals, especially among those who belong to high-risk groups such as truck drivers and prostitutes, provides an opportunity to educate the whole country on HIV/AIDS issues and reduce HIV incidences in India. However, the effect of radio in increasing HIV/AIDS knowledge is less than that of newspapers (Table 4). The information broadcasted on radio channels has positive effects in increasing knowledge and reducing AIDS stigma among both men and women, but the effect is nominal. The nominal effect of radio is due to its low popularity in urban areas, where most individuals resort to watching television. However, radio broadcasting has the potential to educate the rural people, the illiterate and others who are at risk of acquiring HIV virus on sexual matters and HIV/AIDS issues; thus, bringing forth positive changes in the behavior of rural men and women. The positive effect of radio on rural people is due to the absence of any other association with the external world in these regions. Thus, rural people attentively listen to radios as a source of entertainment and as a source of outside information.

The effect of radio, displayed in Table 4, shows in increasing HIV awareness and knowledge among men is less than that of women. For instance, women who listen to radio at least once a week are $6.9 \%$ more likely to have heard of AIDS where as men who listen to radio at least once a week are only $3.7 \%$ more likely to have heard of AIDS. Similarly, women listening to radios are $4.6 \%$ more likely to know that having few sex partners reduces ones chances of acquiring HIV infection, but this number is merely $2.7 \%$ for men. Thus, current radio HIV campaigns have been unsuccessful in targeting men, who are usually the decision-makers in sexual relationships. However, the role of radio in dismantling HIV-related stigma is lower for women. Only $2.7 \%$ of women radio listeners are likely to know that a healthy looking person can have AIDS, while the number is $3.2 \%$ for men. This is similar to the effect of newspapers in reducing HIV stigma in India. It is much more difficult to change previously held misconceptions about AIDS among women than among men. Also, 3.6\% of the women who regularly listen to radios are likely to know that sharing food with an infected person does not transmit AIDS, while the number is $4.7 \%$ for men. These numbers are extremely low for both men and women. Hence, it is essential to continue modifying HIV/AIDS knowledge dissemination programs broadcasted on radios, so that it reaches more people and improves HIV/AIDS knowledge, especially among rural and poor individuals because of limited access to television and newspapers among these groups. 
Indian people's cultures and traditions vary widely across the nation. More than 50 different languages and dialects are spoken in the country. Language barriers across different states and regions hinder the ability of radio programs in reaching individuals with different backgrounds and experiences. Thus, the success of radio campaigns depends on each state's individual response based on its specific HIV-related issue, brought forth in the language of its individuals. In the recent decade, the number of households with cars has increased considerably and since radios are mostly accessed during traveling, there is strong hope that radio shows will be useful in increasing HIV/AIDS knowledge among all Indians. Therefore, state governments and AIDS campaigns need to redirect radio programming and change its course in order to increase radio's effectiveness in increasing AIDS knowledge.

\subsection{Television $(F W T)$}

In the last few decades, increased modernization and globalization in India has acquainted Indians with the western culture and wrecked social barriers that hindered open communication in the past. The portrayal of women on television has shifted from the household goddess to working executive leaders. The talks and acts of sex are still limited on Indian television programs, but easy access to western shows has increased awareness about sex, condoms, STDs and AIDS among urban men and women. The influence of television on Indian people is evident from the emulations of dresses worn by actors among the general population and interactions between people that mostly revolves around top television shows and movies. Thus, the spread of television in India has changed the whereabouts of the country with respect to gender roles, communication, education, community preference, and all other aspects that affects an individual's life. The probit results show that television does have an impact in increasing HIV/AIDS knowledge, but the impact has not been high.

Television has proved to be the best media source in creating general awareness about HIV/AIDS. For instance, in Table 4 the likelihood of having heard of AIDS is 12.3\% higher among women who watch television at least once a week compared to women who watch television less than once a week. For men, the likelihood percentage is $5.4 \%$. The role of television in eliminating HIV/AIDS stigma is still a challenge. Only $3.6 \%$ of the women and $4.9 \%$ of the men who watched television regularly were likely to know that a healthy looking person could have AIDS. Also, $6.9 \%$ of women and $5.6 \%$ of men television viewers were likely to know that AIDS cannot be transmitted by sharing food with an infected person. Even though these numbers are much better when compared to radio's success in reducing HIV stigma, there are low in absolute terms. The need to drastically change HIV/AIDS stigma in India stems from the growing HIV epidemic, predominantly caused due to fear of HIV infection. Television campaigns have been successful in promoting knowledge on condom use among both men and women-women television watchers are $7.5 \%$ more likely to know that condom use helps in AIDS prevention. However, knowledge on the fact that few sexual partners reduce the chances of HIV infection is negligibly promoted through television programming. Thus, either AIDS campaigns on television are not providing accurate information on AIDS or other television shows are depicting impressions that lead to opposing knowledge on AIDS. Therefore, if the problem lies in AIDS advertisement and campaigns, they should be modified to provide accurate, complete and objective AIDS-related knowledge directly through true stories and official statistics. However, if the 
AIDS knowledge concern stems due to other television shows, theses shows can perhaps be censored to avoid AIDS misconception among the general population. Both these measures are essential because of the high influence of television on Indian people.

The minimal impact of television in promoting HIV knowledge in the past is because of several factors, however, the two main reasons are- the extensive censorship of Indian television content and limited access to television, especially in rural areas. The first problem of huge censorship is mostly solved by improved globalization. However, the second problem of limited access to television still exists. Most villagers in India are too poor to afford regular electricity and cable payments. Therefore, it would be in the best interest of the government to provide amenities such as electricity and water for rural Indians, most of who live way below the poverty line, in order to improve the country's AIDS situation. Television access will improve knowledge not only on AIDS, but also on other STDs, female feticide, changing perceptions of women, importance of education, and other factors that will ultimately lead to India's growth and success.

\subsection{Interaction Effects}

It is reasonable to assume that media exposure may exhibit different degrees of association with respect to both educational levels and work status. Hence, Table 4 also displays interactions effects between these variables and media exposure.

Work status seems to play a more important role for women relative to men. That is, regardless of working status, the degree to which media exposure affects HIV related knowledge in men is the same. Working women, on the other hand, are significantly impacted by media exposure more so than women that do not work. Most interaction coefficients between media exposure and working status for women are positive and significant. This result is interesting and might indicate that working women have more chances to discuss HIV related news with co-workers, which augments both their exposure to media as well as the quality of the information they process. Also, these results indicate that changing social norms in order to empower women to go to work might be an important avenue for public policy to pursue.

Surprisingly, the interaction between educational levels and media exposure via newspapers or radio either display no significant effects or, in some cases, negative effects. This implies that more education acts as a deterrent to media exposure in affecting HIV related knowledge. At first, these results might appear counter intuitive; however, it may just indicate a possible decreasing role of media in propagating HIV related knowledge in more educated individuals. That is, media becomes a less important source of information regarding HIV once individuals are already somewhat knowledgeable about the disease. As long as knowledge about HIV is positively correlated with educational levels (see Appendix), media exposure can only play a limited role (TV being the possible exception), which is not the case for less educated individuals.

\subsection{Other Specifications}

The Ordered probit regression explains the impact of media sources, such as newspaper, radio and television on the varying quality of AIDS knowledge. Even though the probit results indicate the effect of media on overall AIDS knowledge, the ordered probit results explain the efficiency of media in 
increasing different levels of AIDS knowledge. The AIDS campaigns and advertisements on television, radio and newspaper are assumed to increase AIDS knowledge only up to a certain level due to limitations and restrictions on what can be depicted and portrayed through media. Thus, the magnitude of the ordered probit results provide an estimation of whether media notably improves the quality of AIDS knowledge, for levels ranging from having heard of AIDS to answering four questions about the infection correctly.

Table 5 displays the marginal effects for each possible outcome. Overall, despite most of the negative effects, newspapers, radios and televisions have a positive and statistically significant impact in improving the quality of AIDS knowledge among Indian inhabitants. The turning point occurs between outcomes 4 and 5, which suggests that comprehensive knowledge is important and that partial knowledge about the disease might be detrimental (relationship is somewhat quadratic).

Table 5. Average partial effects of media on HIV quality of knowledge.

\begin{tabular}{ccccccc}
\hline \multirow{2}{*}{ Outcomes } & \multicolumn{3}{c}{ Males } & \multicolumn{3}{c}{ Females } \\
\cline { 2 - 6 } & Newspaper & Radio & Television & Newspaper & Radio & Television \\
\hline Outcome 1 & -0.0163 & -0.0091 & -0.0121 & -0.0269 & -0.0177 & -0.0269 \\
& $(0.000)$ & $(0.000)$ & $(0.000)$ & $(0.000)$ & $(0.000)$ & $(0.000)$ \\
Outcome 2 & -0.0239 & -0.0126 & -0.0163 & -0.0296 & -0.0181 & -0.0258 \\
& $(0.000)$ & $(0.000)$ & $(0.000)$ & $(0.000)$ & $(0.000)$ & $(0.000)$ \\
Outcome 3 & -0.0419 & -0.0218 & -0.0274 & -0.0262 & -0.0156 & -0.0202 \\
& $(0.000)$ & $(0.000)$ & $(0.000)$ & $(0.000)$ & $(0.000)$ & $(0.000)$ \\
Outcome 4 & -0.0368 & -0.0206 & -0.0232 & -0.0050 & -0.0028 & -0.0001 \\
& $(0.000)$ & $(0.000)$ & $(0.000)$ & $(0.000)$ & $(0.000)$ & $(0.000)$ \\
Outcome 5 & 0.1191 & 0.0642 & 0.0793 & 0.0879 & 0.0544 & 0.0731 \\
& $(0.000)$ & $(0.000)$ & $(0.000)$ & $(0.000)$ & $(0.000)$ & $(0.000)$ \\
$N$ & 63594 & 63625 & 63629 & 83993 & 84028 & 84034 \\
Pseudo- $R^{2}$ & 0.0948 & 0.0919 & 0.0918 & 0.1034 & 0.1019 & 0.1022 \\
\hline
\end{tabular}

Robust $p$-values in parenthesis.

It is evident that media has positive and significant effect in improving the quality of AIDS knowledge among Indian men and women, after controlling for education, wealth, location, marital status, work status, state, religion and age. However, the negative coefficient for the role of media in increasing general AIDS awareness but not providing any quality AIDS knowledge might seem fairly peculiar. A possible justification for the negative coefficient is that AIDS portrayal on television shows and ads always provide at least one accurate detail on AIDS and hence it is unlikely that media will increase general AIDS awareness but not provide a single fact about the disease. Thus, the ordered probit analysis provides a deeper understanding of the impact of media on AIDS knowledge and offers some evidence that media might confuse people's AIDS knowledge levels. Therefore, AIDS organizations and governmental programs should either rethink the use of their resources in media campaigns or modify these campaigns to increase their consistency of information on Indians. These results are somewhat in line with Pallikadavath, Sreedharan, and Stones [12].

As a final check, we estimate average partial effects of access to media for different segments of our sample. Table 6 displays the results for males and females living in both urban and rural settings. 
This gender and location of residence separation is important for two reasons. First, it has been well documented that access to media may be very different depending on location of residence (Chatterjee [11]). Secondly, gender differences in terms of AIDS education and AIDS knowledge also differ in regards to location of residence (Pallikadavath, Sreedharan, and Stones [12]). The results in Table 6 indicate that in all cases, access to media exhibits a positive influence in AIDS related knowledge. Also, whenever there is a substantial difference in effects, the likelihood of better knowledge is larger in rural areas relative to urban.

Table 6. Media access and HIV knowledge by location of residence.

\begin{tabular}{|c|c|c|c|c|}
\hline \multirow{2}{*}{ Variable } & \multicolumn{2}{|c|}{ Males } & \multicolumn{2}{|c|}{ Females } \\
\hline & Urban & Rural & Urban & Rural \\
\hline \multicolumn{5}{|c|}{ Awareness } \\
\hline Newspapers & $\begin{array}{l}0.0331 * \\
(0.0025)\end{array}$ & $\begin{array}{l}0.1011 * \\
(0.0046)\end{array}$ & $\begin{array}{l}0.0633 * \\
(0.0033)\end{array}$ & $\begin{array}{l}0.1112 * \\
(0.0061)\end{array}$ \\
\hline Radio & $\begin{array}{l}0.0184 * \\
(0.0019)\end{array}$ & $\begin{array}{l}0.0537 * \\
(0.0036)\end{array}$ & $\begin{array}{l}0.0443 * \\
(0.0028)\end{array}$ & $\begin{array}{c}0.0924 * \\
(0.0036)\end{array}$ \\
\hline Television & $\begin{array}{l}0.0241 * \\
(0.0028)\end{array}$ & $\begin{array}{l}0.0796 * \\
(0.0041)\end{array}$ & $\begin{array}{l}0.0934 * \\
(0.0039)\end{array}$ & $\begin{array}{l}0.1406 * \\
(0.0039)\end{array}$ \\
\hline \multicolumn{5}{|c|}{ Condom use } \\
\hline Newspapers & $\begin{array}{l}0.0493 * \\
(0.0050)\end{array}$ & $\begin{array}{l}0.0803 * \\
(0.0056)\end{array}$ & $\begin{array}{l}0.0786 * \\
(0.0048)\end{array}$ & $\begin{array}{l}0.0646 * \\
(0.0063)\end{array}$ \\
\hline Radio & $\begin{array}{l}0.0257 * \\
(0.0036)\end{array}$ & $\begin{array}{l}0.0458 * \\
(0.0046)\end{array}$ & $\begin{array}{l}0.0440 * \\
(0.0043)\end{array}$ & $\begin{array}{c}0.0575 * \\
(0.0050)\end{array}$ \\
\hline Television & $\begin{array}{l}0.0252 * \\
(0.0056)\end{array}$ & $\begin{array}{c}0.0501 * \\
(0.0053)\end{array}$ & $\begin{array}{l}0.0695 * \\
(0.0067) \\
\end{array}$ & $\begin{array}{l}0.0843 * \\
(0.0057)\end{array}$ \\
\hline \multicolumn{5}{|c|}{ Number of sexual partners } \\
\hline Newspapers & $\begin{array}{l}0.0409 * \\
(0.0044)\end{array}$ & $\begin{array}{l}0.0602 * \\
(0.0049)\end{array}$ & $\begin{array}{l}0.0635 * \\
(0.0043)\end{array}$ & $\begin{array}{l}0.0610 * \\
(0.0058)\end{array}$ \\
\hline Radio & $\begin{array}{l}0.0214 * \\
(0.0032)\end{array}$ & $\begin{array}{l}0.0332 * \\
(0.0042)\end{array}$ & $\begin{array}{l}0.0439 * \\
(0.0037)\end{array}$ & $\begin{array}{l}0.0471 * \\
(0.0046)\end{array}$ \\
\hline Television & $\begin{array}{l}0.0340 * \\
(0.0052)\end{array}$ & $\begin{array}{l}0.0263 * \\
(0.0048)\end{array}$ & $\begin{array}{l}0.0405 * \\
(0.0059)\end{array}$ & $\begin{array}{l}0.0501 * \\
(0.0053)\end{array}$ \\
\hline \multicolumn{5}{|c|}{ Sharing food } \\
\hline Newspapers & $\begin{array}{l}0.0744 * \\
(0.0055)\end{array}$ & $\begin{array}{l}0.0880 * \\
(0.0063)\end{array}$ & $\begin{array}{l}0.0673 * \\
(0.0043)\end{array}$ & $\begin{array}{c}0.0657 * \\
(0.0060)\end{array}$ \\
\hline Radio & $\begin{array}{l}0.0432 * \\
(0.0039)\end{array}$ & $\begin{array}{l}0.0513 * \\
(0.0052)\end{array}$ & $\begin{array}{l}0.0390 * \\
(0.0038)\end{array}$ & $\begin{array}{c}0.0361 * \\
(0.0048)\end{array}$ \\
\hline Television & $\begin{array}{l}0.0466 * \\
(0.0061)\end{array}$ & $\begin{array}{l}0.0595 * \\
(0.0059)\end{array}$ & $\begin{array}{l}0.0506 * \\
(0.0059)\end{array}$ & $\begin{array}{l}0.0775 * \\
(0.0055)\end{array}$ \\
\hline
\end{tabular}

Robust standard errors in parenthesis. * Significant at $1 \%$ level. 
Table 6. Cont.

\begin{tabular}{ccccc}
\hline \multirow{2}{*}{ Variable } & \multicolumn{2}{c}{ Males } & \multicolumn{2}{c}{ Females } \\
\cline { 2 - 5 } & Urban & Rural & Rural \\
\hline \multirow{2}{*}{ Newspapers } & $0.0663 *$ & $0.0835^{*}$ & $0.0565 *$ & $0.0509 *$ \\
& $(0.0057)$ & $(0.0064)$ & $(0.0048)$ & $(0.0064)$ \\
Radio & $0.0304 *$ & $0.0378 *$ & $0.0266 *$ & $0.0277 *$ \\
& $(0.0042)$ & $(0.0054)$ & $(0.0043)$ & $(0.0052)$ \\
Television & $0.0410 *$ & $0.0555^{*} *$ & $0.0311 *$ & $0.0376 *$ \\
& $(0.0064)$ & $(0.0062)$ & $(0.0065)$ & $(0.0059)$ \\
\hline
\end{tabular}

Robust standard errors in parenthesis. * Significant at $1 \%$ level.

\section{Conclusions}

The results exemplify the importance of analyzing the effect of media on improving AIDS related knowledge. Media sources such as television are helpful in improving AIDS-related knowledge among Indians. Sources such as radio and newspapers have lower impact in educating individuals on AIDS prevention and transmission modes because of possibly low literacy rates in India. Moreover, the effect of media in removing AIDS-associated stigma is very low. Thus, AIDS stigma still exists, especially in rural areas and among uneducated poor Indians. The low effect of media on improving AIDS-related knowledge is also possibly due to cultural taboos and conservative government actions, both of which obstruct the objective portrayal of AIDS through media. Thus, development of media sources such as television in rural areas and change in the conservative attitude of political leaders could possibly result in easy access to accurate AIDS information among all Indians through television, radio, and newspapers.

Previous studies have investigated the effect of socioeconomic factors on AIDS knowledge and sexual behavior in India. It would be interesting to investigate the association between HIV knowledge and sexual behavior in India controlling for socioeconomic characteristics and media access. This would allow one to assess the direct and indirect role of media on sexual behavior as well as the direct role of HIV knowledge on sexual behavior. We leave both of these questions for a future study. Another useful extension to the results of this paper would be to explore the difference in the effect of knowledge campaigns on educated and uneducated individuals. It is very likely that knowledge campaigns prove to be highly effective among educated people while having no long-term effect on uneducated members of society.

Also, a study on the varying effect of knowledge on urban versus rural people will probably highlight the day-to-day difficulties faced by rural members of society that make it difficult for them to change their risky sexual behavior. Even though we have attempted to shed some light into this issue, more substantial analysis is needed.

The AIDS problem is highly misunderstood in India because of misreported information and corruption in data processing. Therefore, a variety of different studies will more accurately unwrap the AIDS problem in India and provide effective solutions to eradicate the problem. 


\section{Conflicts of Interests}

The authors declare no conflict of interest.

\section{References}

1. UNAIDS. Global Facts \& Figures. Available online: http://data.unaids.org/pub/FactSheet/ 2009/20091124_FS_global_en.pdf (accessed on 15 November 2010).

2. National Intelligence Council. "The Next Wave of HIV/AIDS: Nigeria, Ethiopia, Russia, India and China". Available online: http://fas.org/irp/nic/hiv-aids.html (accessed on 15 November 2010).

3. Aggarwal, R.M.; Rous, J.J. Awareness and quality of knowledge regarding HIV/AIDS among women in India. J. Dev. Stud. 2006, 42, 371-401.

4. Ghosh, J.A. Geographical perspective on HIV/AIDS in India. Geogr. Rev. 2002, 92, 114-126.

5. Kumar, M.S.; Mudaliar, S.; Daniels, D. Community-based outreach HIV intervention for street-recruited drug users in Madras, India. Public Health Rep. 1998, 113, 58-66.

6. Eberstadt, N. The future of AIDS. Foreign Aff. 2002, 81, 22-45.

7. Keshavan, K. AIDS in India: When Denial kills. Home Health Care Manag. Pract. 2007, 20, 21-26.

8. De Araujo, P. Socio-economic status, HIV/AIDS knowledge and stigma, and sexual behavior in India. Indian Dev. Rev. 2013, 11, 71-87.

9. Jensen, R.; Oster, E. The power of TV: Cable television and women's status in India. Quart. J. Econ. 2009, 124, 1057-1094.

10. Johnson, K. Media and social change: The modernizing influences of television in rural India. Media Cult. Soc. 2001, 23, 147-169.

11. Chatterjee, P. Spreading the word about HIV/AIDS in India. Lancet 2003, 361, 1526.

12. Pallikadavath, S.; Sreedharan, C.; Stones, R.W. Sources of AIDS awareness among women in India. AIDS Care 2006, 18, 44-48.

13. Keating, J.; Meekers, D.; Adewuyi, A. Assessing effects of a media campaign on HIV/AIDS awareness and prevention in Nigeria: Results from the VISION Project. BMC Public Health 2006, $6,1-12$.

14. Bessinger, R.; Katende, C.; Gupta, N. Multi-media campaign exposure effects on knowledge and use of condoms for STI and HIV/AIDS prevention in Uganda. Eval. Progr. Plan. 2004, 27, 397-407.

15. Jesmin, S.S.; Chaudhuri, S.; Abdullah, S. Educating women for HIV prevention: Does exposure to mass media make them more knowledgeable? Health Care Women Int. 2013, 34, 303-331.

16. Bertrand, J.T.; Anhanq, R. The effectiveness of mass media in changing HIV/AIDS-related behaviour among young people in developing countries. World Health Organ. Tech. Rep. Ser. 2006, 938, 205-241.

17. Lambert, H.; Wood, K. A comparative analysis of communication about sex, health and sexual health in India and South Africa: Implications for HIV prevention. Cult. Health Sex. 2005, 7 , $527-541$. 
18. Ghosh, J.; Wadhwa, V.; Kalipeni, E. Vulnerability to HIV/AIDS among women of reproductive age in the slums of Dehli and Hyderabad, India. Social Sci. Med. 2009, 68, 638-642.

19. Gupta, D.; Lhwa, D.; Viswanath, R.; Jacob, S.M.; Parameshwari, S.; Radhakrishnan, R.; Seidel, K.; Frenkel, L.M.; Samuel, N.M.; Melvin, A.J. Effectiveness of antenatal group HIV voluntary counseling and testing services in rural India. AIDS Educ. Prev. 2007, 19, 187-197.

20. National Family Health Survey, India. Available online: http://www.rchiips.org/nfhs/ nfhs3.shtml\#SAMPLING (accessed on 15 August 2009).

21. Jayasree, A.K. Searching for justice for body and self in a coercive environment: Sex work in Kerala, India. Reprod. Health Matters 2004, 12, 58-67.

22. Wooldridge, J.M. Introductory Econometrics: A Modern Approach, 4th ed.; South-Western Cengage Learning: Mason, OH, USA, 2009.

23. Bartus, T. Estimation of marginal effects using margeff. Stata J. 2005, 5, 309-329.

24. De Souza, R. The construction of HIV/AIDS in Indian newspapers: A frame analysis. Health Commun. 2007, 21, 257-266. 


\section{Appendix: Average Partial Effects Controls Only (All Specification)}

Table A1. Average partial effects of media on HIV awareness.

\begin{tabular}{|c|c|c|c|c|c|c|}
\hline \multirow{2}{*}{ Variable } & \multicolumn{3}{|c|}{ Males } & \multicolumn{3}{|c|}{ Females } \\
\hline & Newspaper & Radio & Television & Newspaper & Radio & Television \\
\hline \multirow[t]{2}{*}{ EDUC_2 } & 0.0667 & 0.0955 & 0.0929 & 0.1464 & 0.1554 & 0.1470 \\
\hline & $(0.000)$ & $(0.000)$ & $(0.000)$ & $(0.000)$ & $(0.000)$ & $(0.000)$ \\
\hline \multirow[t]{2}{*}{ EDUC_3 } & 0.1323 & 0.1876 & 0.1834 & 0.2810 & 0.3103 & 0.2992 \\
\hline & $(0.000)$ & $(0.000)$ & $(0.000)$ & $(0.000)$ & $(0.000)$ & $(0.000)$ \\
\hline \multirow[t]{2}{*}{ EDUC_4 } & 0.1829 & 0.2352 & 0.2311 & 0.4024 & 0.4333 & 0.4247 \\
\hline & $(0.000)$ & $(0.000)$ & (0.000) & $(0.000)$ & $(0.000)$ & $(0.000)$ \\
\hline \multirow[t]{2}{*}{ WEALTH_2 } & 0.0617 & 0.0647 & 0.0555 & 0.0884 & 0.0844 & 0.0668 \\
\hline & $(0.000)$ & $(0.000)$ & $(0.000)$ & $(0.000)$ & $(0.000)$ & $(0.000)$ \\
\hline \multirow[t]{2}{*}{ WEALTH_3 } & 0.0949 & 0.1015 & 0.0836 & 0.1629 & 0.1586 & 0.1184 \\
\hline & $(0.000)$ & $(0.000)$ & $(0.000)$ & $(0.000)$ & $(0.000)$ & $(0.000)$ \\
\hline \multirow[t]{2}{*}{ WEALTH_4 } & 0.1186 & 0.1289 & 0.1033 & 0.2266 & 0.2255 & 0.1615 \\
\hline & $(0.000)$ & $(0.000)$ & $(0.000)$ & $(0.000)$ & $(0.000)$ & $(0.000)$ \\
\hline \multirow[t]{2}{*}{ WEALTH_5 } & 0.1387 & 0.1542 & 0.1253 & 0.2711 & 0.2800 & 0.2027 \\
\hline & $(0.000)$ & $(0.000)$ & $(0.000)$ & $(0.000)$ & $(0.000)$ & $(0.000)$ \\
\hline \multirow[t]{2}{*}{ LOC } & 0.0317 & 0.0350 & 0.0278 & 0.0470 & 0.0530 & 0.0358 \\
\hline & $(0.000)$ & $(0.000)$ & $(0.000)$ & $(0.000)$ & $(0.000)$ & $(0.000)$ \\
\hline \multirow[t]{2}{*}{ MS_2 } & 0.0148 & 0.0145 & 0.0152 & -0.0052 & -0.0090 & -0.0044 \\
\hline & $(0.000)$ & $(0.000)$ & $(0.000)$ & $(0.158)$ & $(0.014)$ & $(0.217)$ \\
\hline \multirow[t]{2}{*}{ MS_3 } & -0.0239 & -0.0259 & -0.0234 & -0.0090 & -0.0117 & -0.0075 \\
\hline & $(0.006)$ & $(0.003)$ & $(0.007)$ & (0.113) & $(0.040)$ & $(0.181)$ \\
\hline \multirow[t]{2}{*}{ WORK_2 } & -0.0064 & -0.0095 & -0.0087 & 0.0051 & 0.0043 & 0.0075 \\
\hline & $(0.065)$ & $(0.006)$ & $(0.012)$ & $(0.020)$ & $(0.049)$ & $(0.001)$ \\
\hline \multirow[t]{2}{*}{ AGE } & -0.0013 & -0.0011 & -0.0009 & 0.0001 & 0.0003 & 0.0004 \\
\hline & $(0.000)$ & $(0.000)$ & $(0.000)$ & $(0.343)$ & $(0.025)$ & $(0.002)$ \\
\hline$N$ & 71730 & 71780 & 71783 & 118138 & 118205 & 118214 \\
\hline Wald $\mathrm{Chi}^{2}$ & 9688 & 9931 & 10315 & 31813 & 32650 & 34147 \\
\hline Pseudo- $R^{2}$ & 0.3564 & 0.3504 & 0.3538 & 0.4027 & 0.4039 & 0.4138 \\
\hline
\end{tabular}

Notes: age squared, state of residence, caste status, and religion used as extra controls in all models above.

Robust $p$-values in parenthesis. APE of AGE calculated at the mean value. 
Table A2. Average partial effects of newspaper on HIV specific knowledge.

\begin{tabular}{|c|c|c|c|c|c|c|c|c|}
\hline \multirow{2}{*}{ Variable } & \multicolumn{4}{|c|}{ Males } & \multicolumn{4}{|c|}{ Females } \\
\hline & $\mathrm{KCU}$ & KSP & KSF & HLP & KCU & KSP & KSF & HLP \\
\hline \multirow[t]{2}{*}{ EDUC_2 } & 0.0432 & 0.0452 & -0.014 & 0.0057 & 0.0310 & 0.0340 & 0.0262 & -0.011 \\
\hline & $(0.019)$ & $(0.008)$ & $(0.416)$ & $(0.768)$ & $(0.079)$ & $(0.033)$ & $(0.108)$ & $(0.483)$ \\
\hline \multirow[t]{2}{*}{ EDUC_3 } & 0.0936 & 0.0861 & 0.0721 & 0.0595 & 0.1501 & 0.1169 & 0.1447 & 0.0784 \\
\hline & $(0.000)$ & $(0.000)$ & $(0.000)$ & $(0.002)$ & $(0.000)$ & $(0.000)$ & $(0.000)$ & $(0.000)$ \\
\hline \multirow[t]{2}{*}{ EDUC_4 } & 0.1310 & 0.1271 & 0.1782 & 0.1561 & 0.2723 & 0.1977 & 0.2696 & 0.2188 \\
\hline & $(0.000)$ & $(0.000)$ & $(0.000)$ & $(0.000)$ & $(0.000)$ & $(0.000)$ & $(0.000)$ & $(0.000)$ \\
\hline \multirow[t]{2}{*}{ WEALTH_2 } & 0.0274 & 0.0158 & 0.0466 & 0.0120 & 0.0257 & 0.0245 & 0.0258 & 0.0082 \\
\hline & $(0.000)$ & $(0.014)$ & $(0.000)$ & $(0.146)$ & $(0.006)$ & $(0.004)$ & $(0.003)$ & $(0.382)$ \\
\hline \multirow[t]{2}{*}{ WEALTH_3 } & 0.0443 & 0.0305 & 0.0794 & 0.0338 & 0.0955 & 0.0582 & 0.0755 & 0.0418 \\
\hline & $(0.000)$ & $(0.000)$ & $(0.000)$ & $(0.000)$ & $(0.000)$ & $(0.000)$ & $(0.000)$ & $(0.000)$ \\
\hline \multirow[t]{2}{*}{ WEALTH_4 } & 0.0706 & 0.0421 & 0.1311 & 0.0658 & 0.1280 & 0.0826 & 0.1206 & 0.0738 \\
\hline & $(0.000)$ & $(0.000)$ & $(0.000)$ & $(0.000)$ & $(0.000)$ & $(0.000)$ & $(0.000)$ & $(0.000)$ \\
\hline \multirow[t]{2}{*}{ WEALTH_5 } & 0.0747 & 0.0562 & 0.1548 & 0.1085 & 0.1619 & 0.1083 & 0.1476 & 0.1171 \\
\hline & $(0.000)$ & $(0.000)$ & $(0.000)$ & $(0.000)$ & $(0.000)$ & $(0.000)$ & $(0.000)$ & $(0.000)$ \\
\hline \multirow[t]{2}{*}{ LOC } & 0.0109 & 0.0011 & 0.0205 & 0.0176 & 0.0169 & -0.0033 & 0.0108 & 0.0162 \\
\hline & $(0.001)$ & $(0.711)$ & $(0.000)$ & $(0.000)$ & $(0.000)$ & $(0.312)$ & $(0.001)$ & $(0.000)$ \\
\hline \multirow[t]{2}{*}{ MS_2 } & 0.0070 & 0.0110 & -0.0139 & 0.0094 & 0.0644 & 0.0392 & -0.0271 & 0.0050 \\
\hline & $(0.140)$ & (0.008) & $(0.007)$ & $(0.080)$ & $(0.000)$ & $(0.000)$ & $(0.000)$ & (0.328) \\
\hline \multirow[t]{2}{*}{ MS_3 } & 0.0103 & -0.0093 & -0.0121 & 0.0013 & 0.0443 & 0.0313 & -0.0340 & 0.0105 \\
\hline & $(0.446)$ & $(0.462)$ & $(0.411)$ & $(0.933)$ & $(0.000)$ & $(0.000)$ & $(0.000)$ & $(0.249)$ \\
\hline \multirow[t]{2}{*}{ WORK_2 } & 0.0081 & 0.0051 & -0.0279 & -0.0052 & -0.0002 & 0.0061 & -0.0029 & 0.0122 \\
\hline & (0.084) & $(0.218)$ & $(0.000)$ & $(0.312)$ & $(0.937)$ & $(0.050)$ & $(0.365)$ & $(0.001)$ \\
\hline \multirow[t]{2}{*}{ AGE } & -0.0002 & 0.0009 & -0.0017 & 0.0012 & 0.0007 & 0.0010 & -0.0009 & -0.0011 \\
\hline & $(0.397)$ & $(0.000)$ & $(0.000)$ & $(0.000)$ & $(0.004)$ & $(0.000)$ & $(0.000)$ & $(0.000)$ \\
\hline$N$ & 63629 & 63673 & 63656 & 63679 & 84050 & 84073 & 84051 & 84081 \\
\hline Wald $\mathrm{Chi}^{2}$ & 5385 & 4491 & 8319 & 5964 & 12357 & 9894 & 11567 & 8704 \\
\hline Pseudo- $R^{2}$ & 0.1015 & 0.1018 & 0.1458 & 0.0954 & 0.1336 & 0.1208 & 0.1417 & 0.0920 \\
\hline
\end{tabular}

Notes: age squared, state of residence, caste status, and religion used as extra controls in all models above.

Robust $p$-values in parenthesis. APE of AGE calculated at the mean value. 
Table A3. Average partial effects of radio on HIV specific knowledge.

\begin{tabular}{|c|c|c|c|c|c|c|c|c|}
\hline \multirow{2}{*}{ Variable } & \multicolumn{4}{|c|}{ Males } & \multicolumn{4}{|c|}{ Females } \\
\hline & KCU & KSP & KSF & HLP & KCU & KSP & KSF & HLP \\
\hline \multirow[t]{2}{*}{ EDUC_2 } & 0.0587 & 0.0622 & 0.0486 & 0.0394 & 0.0686 & 0.0536 & 0.0538 & 0.0210 \\
\hline & $(0.000)$ & $(0.000)$ & $(0.000)$ & $(0.000)$ & $(0.000)$ & $(0.000)$ & $(0.000)$ & $(0.001)$ \\
\hline \multirow[t]{2}{*}{ EDUC_3 } & 0.1371 & 0.1268 & 0.1675 & 0.1223 & 0.2042 & 0.1496 & 0.1866 & 0.1185 \\
\hline & $(0.000)$ & $(0.000)$ & $(0.000)$ & $(0.000)$ & $(0.000)$ & $(0.000)$ & $(0.000)$ & $(0.000)$ \\
\hline \multirow[t]{2}{*}{ EDUC_4 } & 0.1825 & 0.1660 & 0.2841 & 0.2229 & 0.3363 & 0.2372 & 0.3158 & 0.2633 \\
\hline & $(0.000)$ & $(0.000)$ & $(0.000)$ & $(0.000)$ & $(0.000)$ & $(0.000)$ & $(0.000)$ & $(0.000)$ \\
\hline \multirow[t]{2}{*}{ WEALTH_2 } & 0.0291 & 0.0171 & 0.0500 & 0.0148 & 0.0224 & 0.0221 & 0.0230 & 0.0056 \\
\hline & $(0.000)$ & $(0.010)$ & $(0.000)$ & $(0.080)$ & $(0.018)$ & $(0.010)$ & $(0.010)$ & $(0.554)$ \\
\hline \multirow[t]{2}{*}{ WEALTH_3 } & 0.0491 & 0.0341 & 0.0861 & 0.0396 & 0.0932 & 0.0559 & 0.0742 & 0.0402 \\
\hline & $(0.000)$ & $(0.000)$ & $(0.000)$ & $(0.000)$ & $(0.000)$ & $(0.000)$ & $(0.000)$ & $(0.000)$ \\
\hline \multirow[t]{2}{*}{ WEALTH_4 } & 0.0793 & 0.0485 & 0.1425 & 0.0762 & 0.1315 & 0.0855 & 0.1243 & 0.0764 \\
\hline & $(0.000)$ & $(0.000)$ & $(0.000)$ & $(0.000)$ & $(0.000)$ & $(0.000)$ & $(0.000)$ & $(0.000)$ \\
\hline \multirow[t]{2}{*}{ WEALTH_5 } & 0.0886 & 0.0665 & 0.1736 & 0.1247 & 0.1756 & 0.1200 & 0.1610 & 0.1281 \\
\hline & $(0.000)$ & $(0.000)$ & $(0.000)$ & $(0.000)$ & $(0.000)$ & $(0.000)$ & $(0.000)$ & $(0.000)$ \\
\hline \multirow[t]{2}{*}{ LOC } & 0.0135 & 0.0030 & 0.0242 & 0.0199 & 0.0234 & 0.0022 & 0.0160 & 0.0202 \\
\hline & $(0.000)$ & $(0.318)$ & $(0.000)$ & $(0.000)$ & $(0.000)$ & $(0.508)$ & $(0.000)$ & $(0.000)$ \\
\hline \multirow[t]{2}{*}{ MS_2 } & 0.0055 & 0.0096 & -0.0149 & 0.0074 & 0.0588 & 0.0348 & -0.0319 & 0.0003 \\
\hline & $(0.242)$ & $(0.021)$ & $(0.004)$ & $(0.170)$ & $(0.000)$ & $(0.000)$ & $(0.000)$ & $(0.953)$ \\
\hline \multirow[t]{2}{*}{ MS_3 } & 0.0062 & -0.0130 & -0.0170 & -0.0038 & 0.0398 & 0.0276 & -0.0384 & 0.0061 \\
\hline & $(0.648)$ & $(0.316)$ & $(0.256)$ & $(0.811)$ & $(0.000)$ & $(0.001)$ & $(0.000)$ & $(0.499)$ \\
\hline \multirow[t]{2}{*}{ WORK_2 } & 0.0032 & 0.0018 & -0.0339 & -0.0099 & -0.0024 & 0.0047 & -0.0038 & 0.0112 \\
\hline & $(0.468)$ & $(0.643)$ & $(0.000)$ & $(0.053)$ & $(0.489)$ & $(0.132)$ & $(0.232)$ & $(0.002)$ \\
\hline \multirow[t]{2}{*}{ AGE } & 0.0001 & 0.0012 & -0.0013 & 0.0016 & 0.0010 & 0.0012 & -0.0007 & -0.0009 \\
\hline & (0.659) & $(0.000)$ & $(0.000)$ & $(0.000)$ & $(0.000)$ & $(0.000)$ & $(0.002)$ & $(0.000)$ \\
\hline$N$ & 63660 & 63704 & 63687 & 63710 & 84085 & 84108 & 84086 & 84116 \\
\hline Wald $\mathrm{Chi}^{2}$ & 5262 & 4377 & 8122 & 5769 & 12323 & 9891 & 11407 & 8592 \\
\hline Pseudo- $R^{2}$ & 0.0991 & 0.0994 & 0.1428 & 0.0922 & 0.1322 & 0.1198 & 0.1395 & 0.0906 \\
\hline
\end{tabular}

Notes: age squared, state of residence, caste status, and religion used as extra controls in all models above.

Robust $p$-values in parenthesis. APE of AGE calculated at the mean value. 
Table A4. Average partial effects of television on HIV specific knowledge.

\begin{tabular}{|c|c|c|c|c|c|c|c|c|}
\hline \multirow{2}{*}{ Variable } & \multicolumn{4}{|c|}{ Males } & \multicolumn{4}{|c|}{ Females } \\
\hline & KCU & KSP & KSF & HLP & KCU & KSP & KSF & HLP \\
\hline \multirow{2}{*}{ EDUC_2 } & 0.0551 & 0.0633 & 0.0535 & 0.0365 & 0.0699 & 0.0561 & 0.0545 & 0.0233 \\
\hline & $(0.000)$ & $(0.000)$ & $(0.000)$ & $(0.000)$ & $(0.000)$ & $(0.000)$ & $(0.000)$ & $(0.000)$ \\
\hline \multirow{2}{*}{ EDUC_3 } & 0.1326 & 0.1275 & 0.1710 & 0.1191 & 0.2055 & 0.1529 & 0.1880 & 0.1220 \\
\hline & $(0.000)$ & $(0.000)$ & $(0.000)$ & $(0.000)$ & $(0.000)$ & $(0.000)$ & $(0.000)$ & $(0.000)$ \\
\hline \multirow{2}{*}{ EDUC_4 } & 0.1781 & 0.1672 & 0.2859 & 0.2188 & 0.3451 & 0.2450 & 0.3203 & 0.2721 \\
\hline & $(0.000)$ & $(0.000)$ & $(0.000)$ & $(0.000)$ & $(0.000)$ & $(0.000)$ & $(0.000)$ & $(0.000)$ \\
\hline \multirow{2}{*}{ WEALTH_2 } & 0.0249 & 0.0145 & 0.0456 & 0.0105 & 0.0146 & 0.0184 & 0.0161 & 0.0034 \\
\hline & $(0.001)$ & $(0.023)$ & $(0.000)$ & $(0.200)$ & $(0.118)$ & $(0.029)$ & $(0.061)$ & $(0.714)$ \\
\hline \multirow{2}{*}{ WEALTH_3 } & 0.0388 & 0.0274 & 0.0739 & 0.0284 & 0.0734 & 0.0459 & 0.0564 & 0.0335 \\
\hline & $(0.000)$ & $(0.000)$ & $(0.000)$ & $(0.000)$ & $(0.000)$ & $(0.000)$ & $(0.000)$ & $(0.000)$ \\
\hline \multirow{2}{*}{ WEALTH_4 } & 0.0634 & 0.0380 & 0.1223 & 0.0579 & 0.0988 & 0.0678 & 0.0949 & 0.0634 \\
\hline & $(0.000)$ & $(0.000)$ & $(0.000)$ & $(0.000)$ & $(0.000)$ & $(0.000)$ & $(0.000)$ & $(0.000)$ \\
\hline \multirow{2}{*}{ WEALTH_5 } & 0.0697 & 0.0534 & 0.1470 & 0.1023 & 0.1367 & 0.0984 & 0.1249 & 0.1112 \\
\hline & $(0.000)$ & $(0.000)$ & & & & $(0.000)$ & $(0.000)$ & $(0.000)$ \\
\hline \multirow{2}{*}{ LOC } & 0.0098 & 0.0004 & 0.0183 & 0.0159 & 0.0148 & -0.0044 & 0.0088 & 0.0162 \\
\hline & $(0.004)$ & $(0.894)$ & $(0.000)$ & & $(0.000)$ & $(0.177)$ & $(0.009)$ & $(0.000)$ \\
\hline \multirow{2}{*}{ MS_2 } & 0.0051 & 0.0093 & -0.0150 & 0.0074 & 0.0589 & 0.0338 & -0.0314 & 0.0003 \\
\hline & $(0.277)$ & $(0.026)$ & $(0.003)$ & $(0.169)$ & $(0.000)$ & $(0.000)$ & $(0.000)$ & $(0.944)$ \\
\hline \multirow{2}{*}{ MS_3 } & 0.0085 & -0.0122 & -0.0144 & -0.0017 & 0.0390 & 0.0257 & -0.0383 & 0.0052 \\
\hline & $(0.531)$ & $(0.347)$ & $(0.332)$ & $(0.914)$ & $(0.000)$ & $(0.002)$ & $(0.000)$ & $(0.568)$ \\
\hline \multirow{2}{*}{ WORK_2 } & 0.0028 & 0.0028 & -0.0341 & -0.0098 & 0.0007 & 0.0065 & -0.0017 & 0.0125 \\
\hline & $(0.531)$ & $(0.478)$ & $(0.000)$ & $(0.057)$ & (0.839) & $(0.038)$ & $(0.580)$ & $(0.000)$ \\
\hline \multirow{2}{*}{ AGE } & 0.0002 & 0.0013 & -0.0012 & 0.0017 & 0.0011 & 0.0013 & -0.0006 & -0.0009 \\
\hline & $(0.342)$ & $(0.000)$ & $(0.000)$ & $(0.000)$ & $(0.000)$ & $(0.000)$ & $(0.010)$ & $(0.001)$ \\
\hline$N$ & 63664 & 63708 & 63691 & 63714 & 84091 & 84114 & 84092 & 84122 \\
\hline Wald $\mathrm{Chi}^{2}$ & 5203 & 4349 & 8136 & 5777 & 12371 & 9780 & 11604 & 8594 \\
\hline Pseudo- $R^{2}$ & 0.0985 & 0.0986 & 0.1424 & 0.0927 & 0.1331 & 0.1188 & 0.1413 & 0.0908 \\
\hline
\end{tabular}

Notes: age squared, state of residence, caste status, and religion used as extra controls in all models above.

Robust $p$-values in parenthesis.APE of AGE calculated at the mean value.

(C) 2014 by the authors; licensee MDPI, Basel, Switzerland. This article is an open access article distributed under the terms and conditions of the Creative Commons Attribution license (http://creativecommons.org/licenses/by/3.0/). 